\title{
Sprite possibly produced by two distinct positive cloud-to-ground lightning flashes
}

\author{
Jing Yang ${ }^{1,2, *}$, Gaopeng Lu ${ }^{1,2}$, Ningyu Liu ${ }^{3}$, Mitsuteru Sato ${ }^{4}$, Guili Feng ${ }^{5}$, Yu Wang ${ }^{6}$, and Jung-Kuang \\ $\mathrm{Chou}^{7}$ \\ ${ }^{1}$ Key Laboratory of Middle Atmosphere and Global Environment Observation (LAGEO), Institute of Atmospheric Physics, \\ Chinese Academy of Sciences, Beijing, China \\ ${ }^{2}$ Collaborative Innovation Center on Forecast and Evaluation of Meteorological Disasters, Nanjing University of Information \\ Science \& Technology, Nanjing, China \\ ${ }^{3}$ Geospace Physics Laboratory, Physics and Space Sciences Department, Florida Institute of Technology, Melbourne, FL, USA \\ ${ }^{4}$ Hokkaido University, Department of Cosmosciences, Sapporo, Japan \\ ${ }^{5}$ Shandong Research Institute of Meteorology, Jinan, China \\ ${ }^{6}$ State Grid Electric Power Research Institute, Wuhan, China \\ ${ }^{7}$ Department of Physics, National Cheng Kung University, Tainan City, Taiwan
}

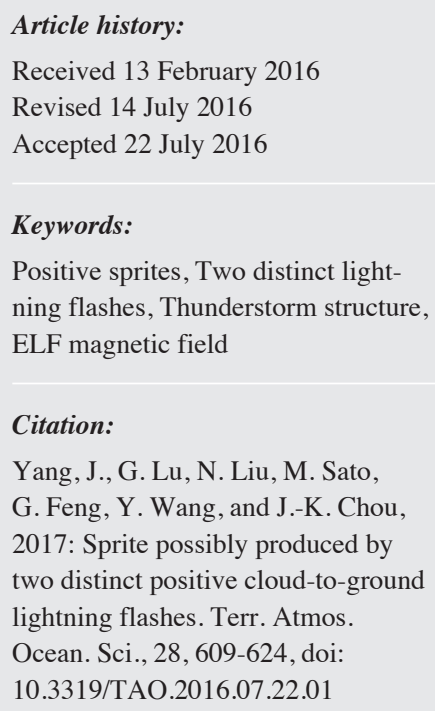

\begin{abstract}
Transient luminous event (TLEs) observations have been conducted in mainland China since 2007, with a number of TLEs documented. This study analyzed a very unusual and unique positive sprite event, that may be produced jointly by two distinct positive cloud-to-ground lightning flashes (+CGs) occurring within a short time difference but with different locations separated by about $27 \mathrm{~km}$. This observation is different from previous studies reporting that most of the sprites were triggered by a single $+\mathrm{CG}$ flash and its possible following continuous current. Detailed analysis on extremely low frequency (ELF) magnetic field shows that combined charge moment change (CMC) due to the two +CGs is smaller $(\sim 1478 \mathrm{C} \mathrm{km})$ than those of the parent CGs for the other two sprites (1582 and $2134 \mathrm{C} \mathrm{km}$, respectively) recorded over the same thunderstorm. The vertical extension and brightness of the sprites correspond well with the CMC of their parent CGs, namely, the larger the CMC value the brighter the sprite, and the larger the $\mathrm{CMC}$ value the larger the vertical extension. Negative lightning flashes dominated during the thunderstorm life cycle. The three sprites occurred during a time window in which both negative and positive flashes were active. The three sprites occurred over the thunderstorm stratiform region.
\end{abstract}

\section{INTRODUCTION}

Transient luminous event (TLEs) is the collective name of several brief light emissions over thunderstorms, normally detected using low-light video cameras (Franz et al. 1990; Sentman et al. 1995; Fukunishi et al. 1996; Wescott et al. 1996; Pasko et al. 2002; Su et al. 2003; Yang et al. 2008, 2013a,b, 2015; Liu et al. 2015a; Sato et al.2017). Up to now, the TLE family includes sprites (Sentman et al. 1995; Lyons 1996; Winckler et al. 1996; Cummer et al. 2006; Yang et al. 2008; Savtchenko et al. 2009; Lang et al. 2010; Suzuki et al. 2011; Boggs et al. 2016; Peng et al. 2017), elves (Emissions of Light and VLF perturbation due to EMP Sources) (Inan

\footnotetext{
* Corresponding author

E-mail:yangj@mail.iap.ac.cn
}

et al. 1996, 1997; Barrington-Leigh et al. 2001; Kuo et al. 2007; Wu et al. 2017), halos (Frey et al. 2007), blue starters, blue jets and gigantic jets (Pasko 2003; Su et al. 2003; Kuo et al. 2009; Chou et al. 2011; Yang and Feng 2012; Liu et al. 2015b). Sprites are usually produced by intense lightning discharges and are observed between about $40-90 \mathrm{~km}$ altitude above thunderstorms (Sentman et al. 1995; Hardman et al. 2000; Neubert et al. 2001; Su et al. 2002; Pinto et al. 2004; Cummer et al. 2006; Van der Velde et al. 2006; Yang et al. 2008, 2013a, 2015; Lu et al. 2017).

Numerous observations indicate that sprites are mostly associated with positive cloud-to-ground (+CG) lightning discharges and their possible subsequent continuing current (especially for long delayed sprite) (Boccippio et al. 1995; 
Lyons 1996; São Sabbas et al. 2003; Cummer and Lyons 2005; Li et al. 2008; Savtchenko et al. 2009; Lang et al. 2010; Yang et al. 2013a, b, 2015). The currently accepted theory of sprites is that they are caused by the quasi-electrostatic (QE) field produced by +CG in the troposphere (Pasko et al. 1997; Liu et al. 2015a). Observations further indicate that a large charge moment change (CMC) (defined as the product of the charge transferred by $\mathrm{CG}$ and the height from which it was removed, the main factor determining the magnitude of the QE field above the thundercloud) of cloud-toground lightning is necessary for sprite initiation (Hu et al. 2002; Cummer and Lyons 2004; Li et al. 2012; Lu et al. 2012, 2013).

Statistical analysis conducted by $\mathrm{Hu}$ et al. (2002) showed that + CGs with a CMC larger than $1000 \mathrm{C} \mathrm{km}$ in less than $6 \mathrm{~ms}$ have more than $90 \%$ possibility to initiate a sprite, while +CGs with less than $600 \mathrm{C} \mathrm{km}$ have less than $10 \%$ possibility for sprite production. Coordinated analysis made by Lu et al. (2013) shows that sprite generation is 90\% likely if a positive stroke occurs with impulse charge moment change (iCMC, defined as the product of the transferred charge within $2 \mathrm{~ms}$ after the return stroke and its original height above the ground) larger than $300 \mathrm{C} \mathrm{km}$, more than three times lower than that in $\mathrm{Hu}$ et al. (2002). The study of $\mathrm{Hu}$ et al. (2002) also indicated that lightning CMC for sprite initiation can be as low as $120 \mathrm{C} \mathrm{km}$ and as high as $3070 \mathrm{C} \mathrm{km}$, indicating that $\mathrm{CMC}$ for sprite production could span a wide range. They also noted that the $120 \mathrm{C} \mathrm{km}$ is probably an exceptional case.

Coordinated analysis by Lu et al. (2013) showed that multiple sprites with dancing features associated with a single lightning flash could be initiated either by distinct strokes of the flash, by a single stroke through a series of current surges superposed on an intense continuous current, or by both. Studies also show that in-cloud (IC) sprite-producing stroke activity could play a role in sprite formation (Ohkubo et al. 2005; Van der Velde et al. 2006; Marshall et al. 2007; Asano et al. 2009).

This study reports on a very interesting and unusual sprite event possibly produced by two distinct positive cloud-to-ground lightning flashes jointly occurring within a short time difference but largely separated in distance (obtained from the lightning detection network). The total CMC of the two +CGs inferred from the extremely-low frequency (ELF) magnetic field was the smallest, compared with those of the parent CGs for two other sprites captured over the same thunderstorm. The vertical extension and brightness of this sprite corresponds well with the small CMC of its parent CG.

\section{OBSERVATIONS}

TLEs occur above thunderstorms and observations from the ground could be conducted hundreds of kilometers away in favorable cloud-free conditions (Franz et al. 1990). It is difficult to choose observation sites in urban areas because of obstruction from high buildings and the background light emission. Even so, several TLE observation stations have been set up since 2007 during which TLE observations were first conducted in China (Yang et al. 2008). In 2012, a TLE station was installed in Dongying (Yellow River Delta Ecology Research Station of Coastal Wetland, Chinese Academy of Sciences), Shandong province, and it is only fifteen kilometers away from the Bohai Sea. There are no villages within five kilometers of the observation site, which is very suitable for sprite optical observation.

The imaging instrument used at this station is the Watec $902 \mathrm{H} 2$ Supreme low-light-level video camera, equipped with a Computar $12 \mathrm{~mm} / \mathrm{F} 0.8$ lens. The camera has a highsensitivity monochrome CCD detector, with minimum illumination of 0.0003 lux at F1.4. In order to obtain as many sprite events as possible, the gain of the camera is set to high, that is, the minimum camera illumination is better than 0.0003 lux at a F0 .8 lens. The observation system frame rate is set to $25 \mathrm{fps}$ (frames per second), with the frame duration less than $40 \mathrm{~ms}$. The pointing direction of the observation system was determined using the background star field ( $\mathrm{Su}$ zuki et al. 2011). The camera was enclosed in a housing to protect it from weather hazards. The camera was remotely controlled from the computer via the internet, allowing real time azimuth adjustment during the observation. The observation system timing was synchronized using the global positioning system (GPS) (Yang et al. 2013a, b, 2015).

Local and global lightning location systems were used for both identifying lightning activity in real time, and for lightning flash characteristics analysis that produced sprites. The lightning location data is obtained from a local lightning detection network, which is used for lightning characteristics analysis associated with sprites and thunderstorms. The lightning detection network covers most provinces in China. In each province the network consists of several (or more than ten) very low-frequency/low-frequency sensors and one data processing center. The lightning location algorithm combined time-of-arrival (TOA) and magnetic-direction-finding (MDF) technology (Cummins et al. 1998). Data from this network was used for characterizing the lightning characteristics (location, types, peak current, etc.) in sprite-producing thunderstorms. The detection efficiency and location error are about $92 \%$ and $760 \mathrm{~m}$, respectively, found using artificially triggered lightning flashes (Liu et al. 2014; Zhang et al. 2014). The lightning detection network sampling rate is $10 \mathrm{MHz}$, the time resolution is $100 \mathrm{~ns}$ and the timing accuracy is on the order of microseconds.

The World Wide Lightning Location Network (WWLLN, http://wwlln.net/) is a very low frequency (VLF, $3-30 \mathrm{kHz}$ ) lightning antenna array, with more than fifty antennas located around the world. One antenna is located at the Institute of Atmospheric Physics, Chinese Academy 
of Sciences (distributed by the University of Washington in Seattle). There are currently four VLF sensors in China, which are located in Beijing, Nanjing, Lanzhou and Hong Kong, respectively. The VLF sensors detect impulsive signals from lightning discharges (lightning radiates electromagnetic power from a few hertz to several hundred megahertz, but the bulk of the energy is located in VLF). The WWLLN uses the group arrival time (TOGA) from at least 5 WWLLN sensors to determine the lightning location (Pan et al. 2009; Abarca et al. 2010; Bovalo et al. 2014). The system provides global lightning and a global map with lightning positions updated every $10 \mathrm{~min}$. Since the WWLLN detection efficiency is not very high, it is used as supplementary data for real-time locating the center of the thunderstorm electrical activity and for subsequent reanalysis.

Besides lightning location data, extremely low frequency (ELF) magnetic field antenna located in Syowa station, Antarctica $\left(39.506^{\circ} \mathrm{E}, 69.018^{\circ} \mathrm{S}\right)$ has been used to identify the parent lightning properties. The Syowa station ELF system frequency range is $1-100 \mathrm{~Hz}$, and the sampling frequency is $400 \mathrm{~Hz}$ ( $2.5 \mathrm{~ms}$ time resolution). There is a low-pass-filter in the main amplifier, whose cutoff frequency is $100 \mathrm{~Hz}$. Two orthogonal search coil sensors with pre-amplifiers are parallel (H-component) and perpendicular (D-component) to the geomagnetic field. More detailed information on the ELF sensor at Syowa station is available in Sato et al. (2003). The magnetic field data is used to infer lightning discharge polarity and the time-integrated $\mathrm{CMC}$ of parent lightning. In addition, the ELF/VLF system located at the Cingcao elementary school, Tainan City, Taiwan $\left(23.08^{\circ} \mathrm{N}, 120.12^{\circ} \mathrm{E}\right)$ has also been used. The ELF/VLF magnetic field and electric field bandwidths are $1.5 \mathrm{~Hz}$ to $15 \mathrm{kHz}$ and $0.1 \mathrm{~Hz}$ to $100 \mathrm{kHz}$, respectively. The sampling rate is $100 \mathrm{kHz}$. More detailed information can be found in Huang et al. (2012) and Chang et al. (2014).

The thunderstorm evolution and structure characteristics are given by Doppler radar $\left(36.803^{\circ} \mathrm{N}, 116.781^{\circ} \mathrm{E}\right.$, altitude $72.85 \mathrm{~m}$ ) which is a useful tool for monitoring mesoscale convective systems (MCSs) (Feng et al. 2009). The radar used in this study is WSR-98D S-band Fully Coherent Doppler Weather radar. The radar data are updated every
$6 \mathrm{~min}$. It has many features including state-of-the-art computerized control, 24-hr operational capability, real-time monitoring, real-time calibration, and high accuracy and reliability (Yang et al. 2013a, b). The radar can operate in two modes, clear-air and precipitation mode. It has two scanning ranges, one is $230 \mathrm{~km}$ and the other is $460 \mathrm{~km}$. In order to obtain accurate information, $230 \mathrm{~km}$ scanning range (with a resolution about $1 \mathrm{~km}$ ) is used in this study. The data was provided by the Shandong Meteorological Bureau and has been used to characterize the thundercloud structure and evolution.

\section{RESULTS}

During the thunderstorm life cycle, three sprites were captured in total in the early morning on 5 August 2012 (time used in this study is local, Local time $=$ UTC $+8 \mathrm{hr}$ ). The first sprite was recorded at 00:23:24.840, which is a positive one lasting two fields (total duration less than $40 \mathrm{~ms}$ ) and will be analyzed in detail in this study. The second sprite was also a positive one with a total duration less than $60 \mathrm{~ms}$, and occurred at 00:27:34.087. The third sprite occurred at 01:21:33.281, lasted three fields with the first two fields containing very dim sprite elements and the third field had a very bright element displaced horizontally from the elements in the first two fields, which has been termed as dancing sprites in the literature (Lyons 1994, 1996; Winckler et al. 1996; Hardman et al. 2000). Detailed analysis on this sprite event can be found in Yang et al. (2015).

\subsection{Characteristics of the Sprite Images}

Images of the three sprites are shown in Fig. 1. Their parent CGs were detected by the local lightning detection network, so the parent CG locations are known (WWLLN did not detect them). Assuming the sprite occurred directly above its parent $\mathrm{CG}$, the sprite location (vertically aligned to the ground) is known. With the known camera system field of view (FOV) information, the observation site elevation and the distance between the sprite and the observation site, the angular separations between the lower edge of the

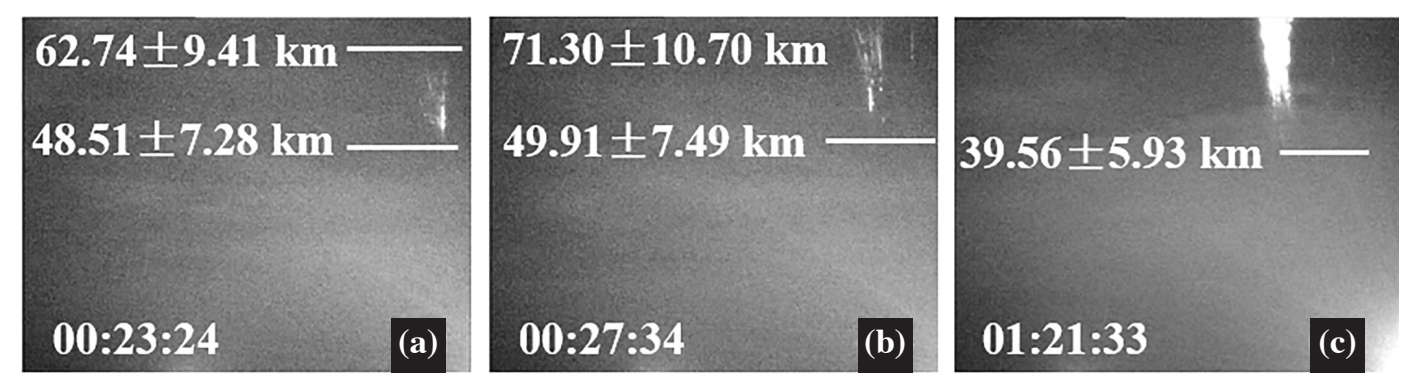

Fig. 1. Video images of sprites recorded in the early morning on 5 August 2012. (a) shows the sprite image analyzed in detail. Only the lower part of the sprite in (c) was recorded by the camera. The observation elevation angle did not change during the entire observation time period. 
sprite and the horizon, and the upper edge of the sprite and the horizon can be obtained. The sprite vertical extension could be estimated using the method mentioned in Hsu et al. (2003) and Yang et al. (2008, 2013a). Assuming a $50 \mathrm{~km}$ uncertainty for the parent lightning location, the bottom and top altitudes for the sprite in Fig. 1a are about $48.51 \pm 7.28$ and $62.74 \pm 9.41 \mathrm{~km}$, respectively, and its vertical extension was smaller than that in Fig. $1 \mathrm{~b}$.

By comparing the optical intensity of the three sprites, the vertical extension of sprite in Fig. 1c may be the largest although its upper part was not captured. It should be noted that the three sprites azimuth did not change much in the camera field of view (see Fig. 1), and thus the camera viewing condition should not change much, either. In addi-

(a)

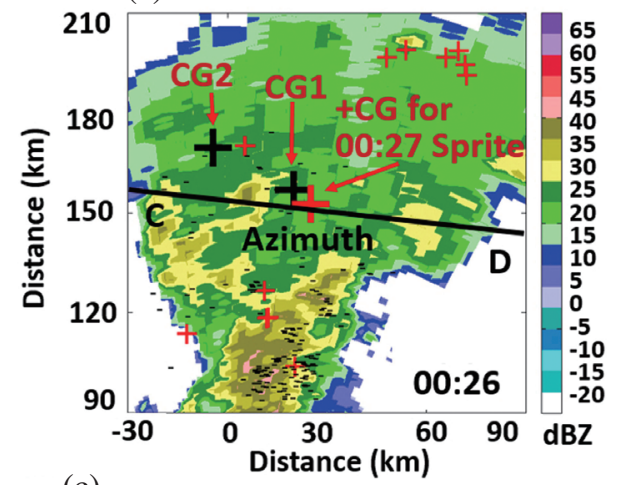

(c)

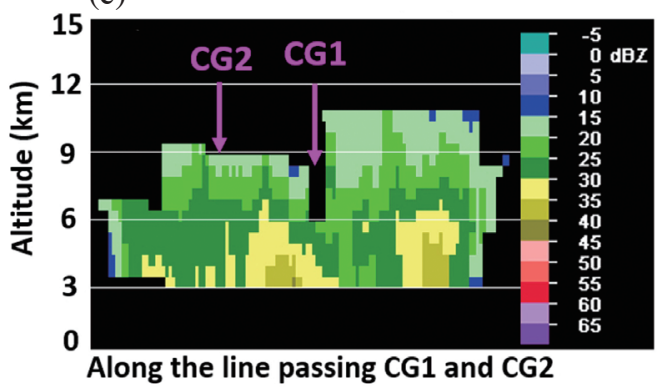

tion, the three sprites were captured using the same camera with the same settings, and thus the camera sensitivity is the same. Therefore, the above discussion leads to a conclusion that the sprite vertical extension in Fig. 1a was the smallest $(14.23 \mathrm{~km})$, compared with the other two sprites recorded over the same thunderstorm. It should be mentioned that the cloud in the camera field of view may lead to underestimating the sprites' vertical extension.

It is interesting to note that the sprite in Fig. 1a might be produced by two distinct positive cloud-to-ground lightning flashes (will be discussed later in this paper), and its vertical extension was estimated using the parent +CG1 location (shown in Fig. 2a) which is closer to the observation site and also closer to the observed sprite azimuth. Similar

(b)

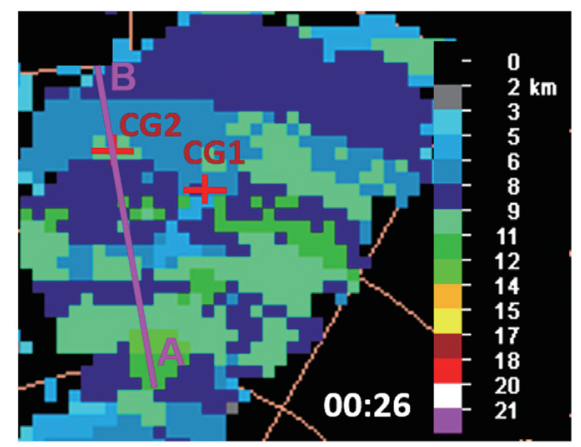

(d)

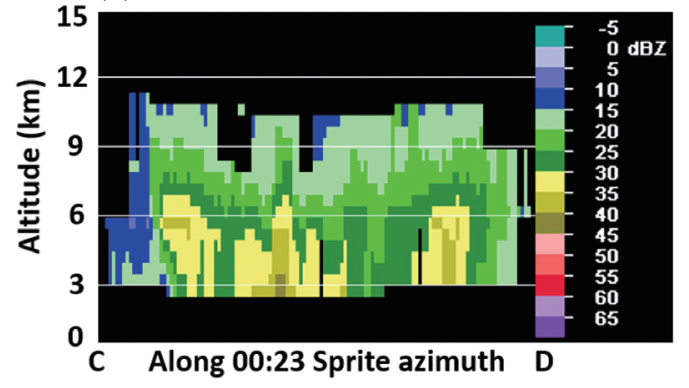

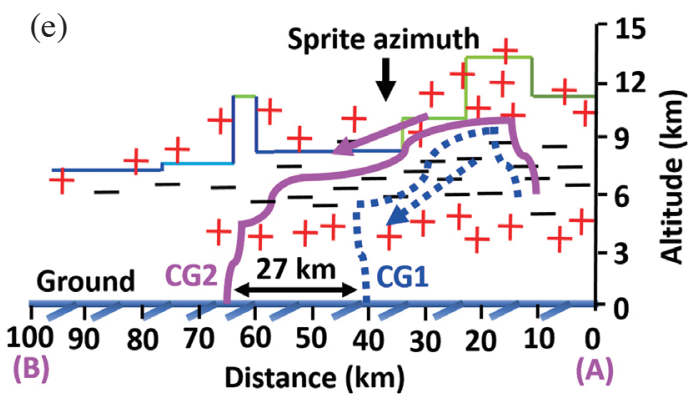

Fig. 2. Thunderstorm structure. (a) Storm base radar reflectivity with elevation angle of $1.5^{\circ}$. The black line CD labeled 'Azimuth' represents the 00:23 sprite azimuth. The locations of return strokes within $10 \mathrm{~min}( \pm 5 \mathrm{~min})$ centered on the sprite event is also shown in the figure. The red " + " stands for positive strokes, and black "-” for negative strokes. The two strokes (labeled as CG1 and CG2, the two big black '+' shown in the figure) immediately before the 00:23 sprite are marked. The parent + CG (the big red ' + ' in the figure) for 00:27 sprite is also shown. (b) Radar echo top overlapped with the locations of strokes CG1 and CG2. (c) Vertical cross section of radar reflectivity along the line passing through CG1 and CG2. CG1 and CG2 are the same as shown in (a) and (b). (d) Vertical cross section of radar reflectivity along 00:23 sprite azimuth [as shown in (a)]. (e) Conceptual model of the thunderstorm charge structure, the return strokes CG1 and CG2 discharges and the 00:23 sprite azimuth are also shown. The letters ' $A$ ' and ' $B$ ' in the abscissa are the same as shown in (b), that is, the abscissa in (e) is along the line 'AB' in (b). 
calculations based on parent $+\mathrm{CG} 2$ were also made and the estimated bottom and top altitudes are about $56.20 \pm 8.43$ and $72.57 \pm 10.89 \mathrm{~km}$, respectively. The vertical extension is about $16.37 \mathrm{~km}$. The results show that sprite vertical extension in Fig. 1a is still the smallest when using the parent $+\mathrm{CG} 2$ location. Assuming that the sprite in Fig. 1a occurred over the middle region between the parent $+\mathrm{CG} 1$ and +CG2, its vertical extension would be $15.30 \mathrm{~km}$ and still be the smallest compared with the other two sprites in Fig. 1. It should be noted that the signal-to-noise ratio shown in Fig. 1 is comparatively low, and the top and bottom terminals cannot be identified precisely in the captured and unprocessed images. Hence, the vertical extension may be underestimated. In order to make a comparatively quantitative analysis on the sprite images, the arbitrary brightness (gray value larger than the background intensity with a pixel value of about 143) of the three sprites (the most intensive frame) were analyzed and shown in Fig. 3. The results indicate that the 00:23 sprite has the smallest number of pixels (4592) which are brighter than the background, the 01:21 sprite has the largest, and the 00:27 sprite is in between. The above results show that the brightness (or intensity) of the 00:23 sprite was the smallest.
High-speed images of sprites show that sprites typically start as a small and dim streak between 70 and $75 \mathrm{~km}$ altitude and develop initially as downward streamers (Stanley et al. 1999; Stenbaek-Nielsen et al. 2000). Sequential images of 00:23 sprite shown in Fig. 4 indicate that this sprite in Fig. 4a indeed started as a small and dim element. However, due to the slow camera speed used in the observation, it is difficult to determine the sprite element propagation direction. The second field for this sprite (Fig. 4b) shows that it mainly developed upward. High-speed images reported by Stenbaek-Nielsen et al. (2010) showed that sprites start with downward-propagating streamer heads at altitudes varying between 66 and $89 \mathrm{~km}$, and in some cases the downward streamers are followed later by upward streamers starting from a lower altitude varying from $64-78 \mathrm{~km}$.

By comparing our results with those from StenbaekNielsen et al. (2010), it was found that the small-scale sprite structures shown in Fig. 4b may be the upward streamers that lead to the observed carrot sprites, in good agreement with the results reported by Stenbaek-Nielsen et al. (2010) in which downward streamers create $\mathrm{C}$ type sprites (namely, columniform sprites, characterized by bright vertical columns in video imagery), while the upward streamers form

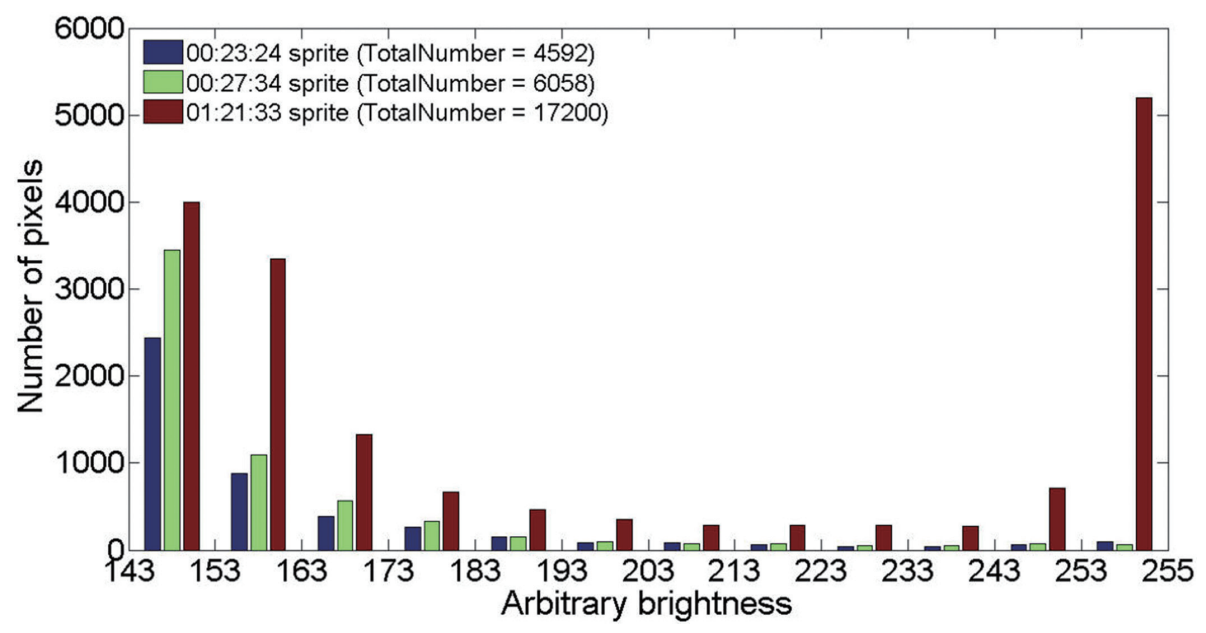

Fig. 3. The arbitrary brightness of the three sprites. (Color online only)

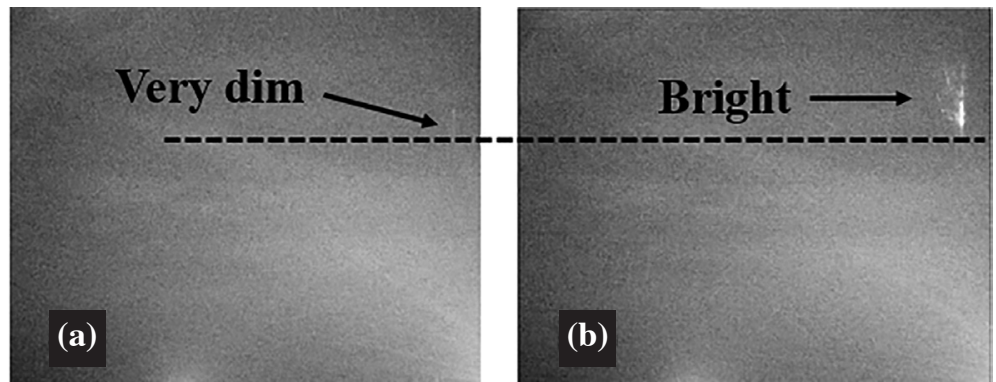

Fig. 4. Video images of the sprite recorded at 00:23 on 5 August 2012. This event consists of two fields. The first field (a) was very dim and the second field (b) was bright. 
the broad diffuse tops of carrot sprites. It should be noted that the bottom and top altitudes of sprites in this study may be underestimated to some extent because of clouds in the camera field of view. Results from the simulation work conducted by Liu et al. (2015c) showed that the diffuse glow preceding the streamer initiation is not bright enough to be detected by the current camera system.

\subsection{Overview of the Thunderstorm Characteristics and Lightning Activity}

The thundercloud structure was obtained using Doppler radar data. This thunderstorm was a mesoscale convective system (lasting more than $10 \mathrm{hr}$ ), which is the main type of summer thunderstorm that occurs in Northern China. Figure 5 shows the radar reflectivity at different times in the sprite-producing thunderstorm, covering the time period during which all the sprites occurred. During the thunderstorm evolution, it was mostly located along the boundary line of Hebei and Shandong provinces. The total surface precipitation in $24 \mathrm{hr}$ (05:00 4 August - 05:00 5 August) in some regions was larger than 100 millimeters and even 204 millimeters, reaching the torrential downpour level.

The radar reflectivity shows that some small convective cells appeared as a disorganized cluster, which can be seen at about 15:00 on 4 August (due to the length limit of the paper, Doppler radar images before 19:00 are not shown). These small cells then merged together and spread to a relatively large area at about 19:00 (Fig. 5a). The storm weakened at about 21:00. Some other small convective cells close to the Doppler radar station developed at 22:03 and became stronger and more extensive at 23:03. The strong radar reflectivity (larger than $30 \mathrm{dBZ}$ ) area became larger at 00:02 than that at 23:03 and then weakened at 00:26. The first sprite was recorded at 00:23:24.840, and about 4 min later the second sprite occurred at 00:27:34.087. The third sprite occurred at 01:21:33.281. 00:23 and 00:27 sprites occurred over the region of interest (labeled as 'ROI' in Fig. $5 \mathrm{~g}$ ). The observation site was outside the figure range, located to the east of the thunderstorm.

Although all of the sprites occurred within a time window less than one hour, the thunderstorm lasted for more than ten hours. In order to avoid subjectivity when grouping the return strokes into one flash, only the strokes that were analyzed are shown in Fig. 6 (the lightning flash rate shows similar evolution, the figure is not shown for the limitation of the paper). The results show that the three sprites occurred within a time window during which both negative and positive strokes were active. The negative strokes dominated during most of the thunderstorm time-evolution. The number of positive strokes was much smaller than the negative ones. The number of positive strokes is multiplied by 10 to clearly show their evolution. The maximum number of strokes occurred within a time window of around 01:00 in the early morning on 5 August. The thunderstorm was compact and strong during this period. At the end of the thunderstorm life cycle (the stratiform region dominated at 04:00 on 5 August), the lightning activity was not active, indicating that the storm was dissipating. The lightning activity is consistent with similar thunderstorms in this region (Liu 2010, PhD thesis).

\subsection{Thunderstorm Structure and Parent Flashes}

Sprites are thought to be produced by the QE field above the thunderstorm due to the fast removal of charges by CG flashes and their possible following continuous current (Pasko et al. 1997; Liu and Pasko 2004; Liu et al. 2015a). By carefully comparing the sprite occurrence time and the lightning location network data and ELF magnetic field recorded at Syowa station, it was found that the sprites occurring at 00:27 and 01:21, respectively, were produced by positive CGs with a single return stroke and the following continuous current. Both of these sprites occurred during the continuous current process with the time delay between the parent CGs and sprites about 14 and $36 \mathrm{~ms}$, respectively.

Compared with the two sprites mentioned above recorded over the same thunderstorm, a sprite occurred at 00:23 that was unusual and unique. Lightning detection network data shows that before this sprite two positive return strokes occurred within a short time difference of $0.344 \mathrm{~ms}$ (see Table 1) (their occurrence times are 00:23:24.7955310 and 00:23:24.7955654, labeled with CG1 and CG2, respectively, in Fig. 2a). The lightning detection network time resolution is $100 \mathrm{~ns}$ (the sampling rate is $10 \mathrm{MHz}$, the timing accuracy is on the order of microseconds), so it can distinguish between the two return strokes. One thing should also be mentioned is that the lightning detection network detected 25723 return strokes during a time period starting from 13:00 on 4 August to 13:00 on 5 August 2012. Of those, 576 strokes had a time difference (between successive strokes) smaller than $1000 \mu$ s (varying from 3 - $999 \mu$ s), indicating that the lightning detection network has the capability to detect strokes with very small time differences.

Although CG1 and CG2 occurred within very short time difference, the distance between the two strokes was largely separated $(\sim 27 \mathrm{~km})$. The distance algorithm usually used for combining return strokes into one flash is $10 \mathrm{~km}$ (Rakov and Uman 2003; Van der Velde et al. 2007). Some researchers also used $1 \mathrm{~km}$ (Shalev et al.2011). The two positive return strokes (labeled with CG1 and CG2 in Fig. 2a) with a separation distance of $27 \mathrm{~km}$ are likely two distinct flashes. The 00:23 sprite was produced by either of the two +CGs or by both.

Previous studies show that sprites can be tens of kilometers away from their parent CGs (Wescott et al. 2001; São Sabbas et al. 2003; Yang et al. 2013a, 2015). Figure 2a 

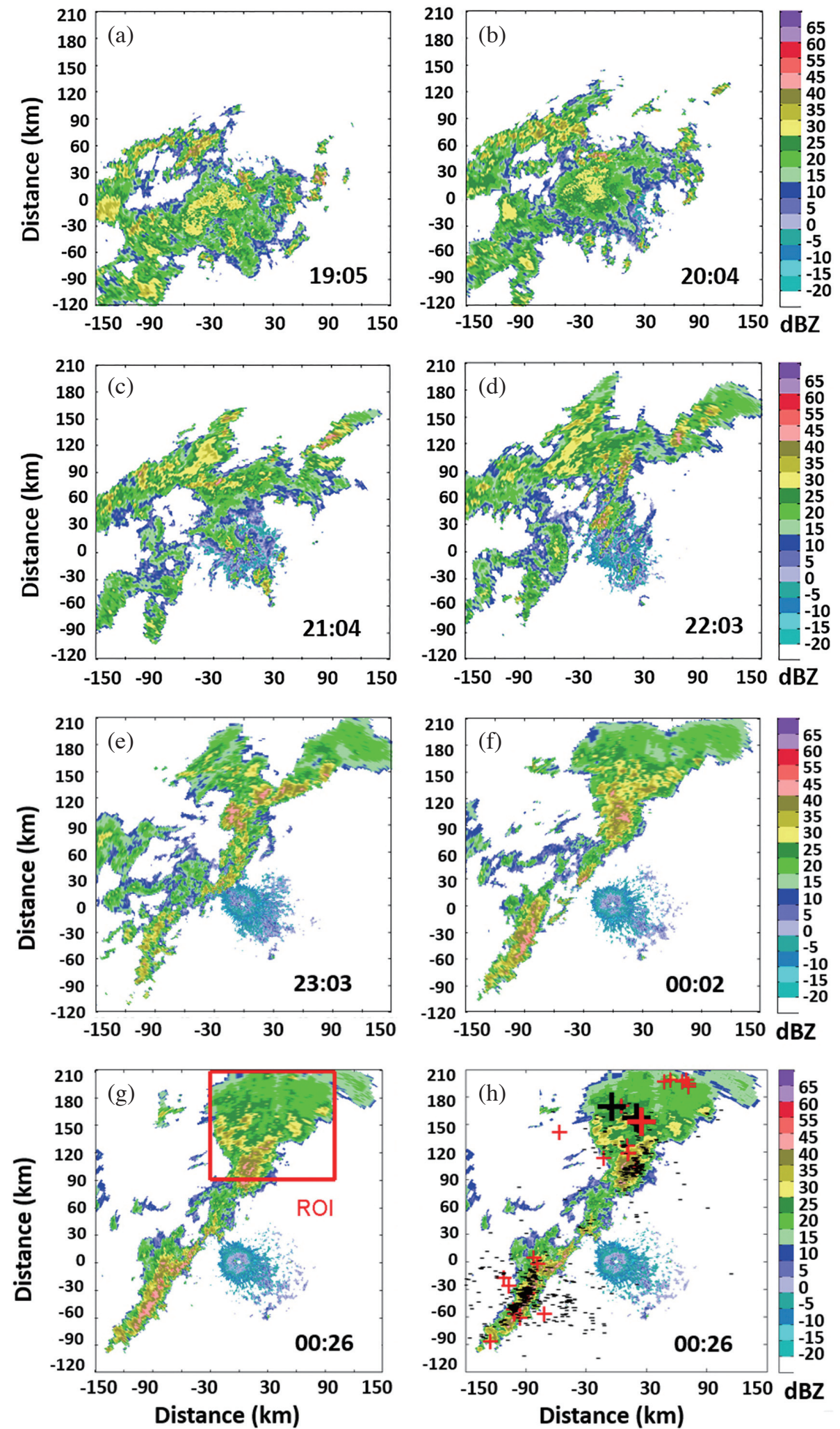

Fig. 5. Base radar reflectivity images obtained at different times with elevation angle of $1.5^{\circ}$ (a) - (h). ROI (region of interest) is the region over which the 00:23 and 00:27 sprites occurred. The "+" stands for positive strokes, and black "-" for negative strokes. The two big black '+' in the figure represent the two strokes before 00:23 sprite. Parent CG for 00:27 sprite is marked by the big red '+'. 


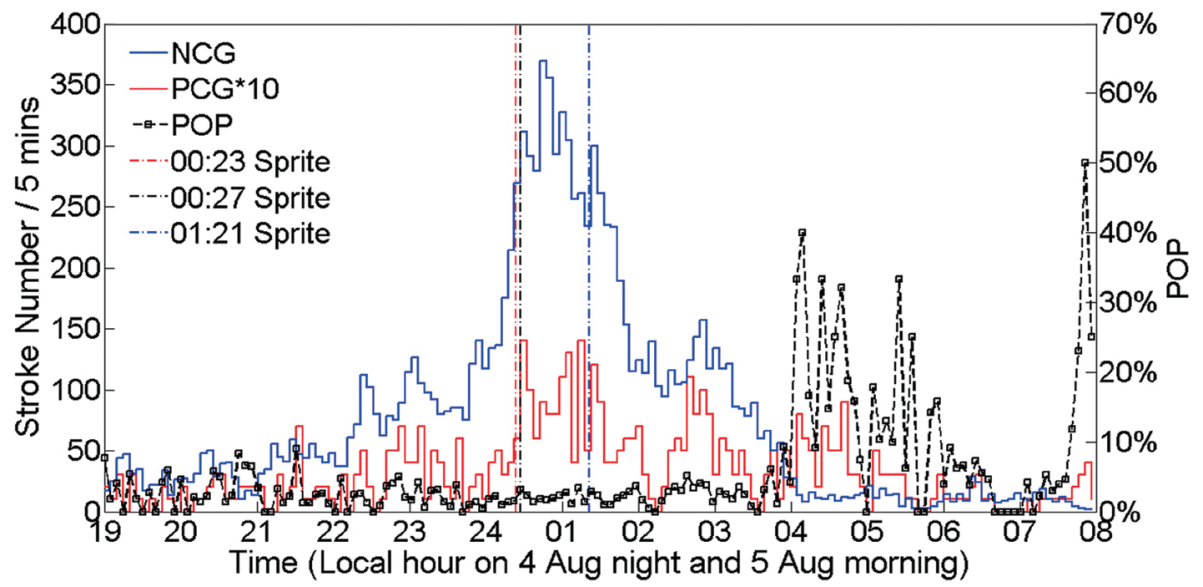

Fig. 6. Counts of the return strokes in 5 min interval during the thunderstorm life cycle. The blue and red lines are the negative and positive strokes, respectively. POP stand for the percentage of positive strokes over total strokes in 5 min interval. The vertical red dashed line, black dashed line and blue dashed line represent for the occurrence time of the 00:23 sprite, 00:27 sprite and 01:21 sprite, respectively. (Color online only)

Table 1. Characteristics of the sprite-associated CGs.

\begin{tabular}{ccccc}
\hline $\begin{array}{c}\text { Parent CG time (Local) (Local = UTC + 8 hours) } \\
\text { (obtained from the local lightning detection network) }\end{array}$ & Parent CG location & $\begin{array}{c}\text { Peak current } \\
(\mathbf{k A})\end{array}$ & $\begin{array}{c}\text { Sprite occurrence time } \\
(\text { Local) }\end{array}$ & $\begin{array}{c}\text { Time delay } \\
(\mathbf{m s})\end{array}$ \\
\hline $00: 23: 24.7955310$ & $117.0036^{\circ} \mathrm{E}, 38.2166^{\circ} \mathrm{N}$ & 45.7 & $00: 23: 24.840$ & 45 \\
$00: 23: 24.7955654$ & $116.7264^{\circ} \mathrm{E}, 38.3295^{\circ} \mathrm{N}$ & 31.9 & & \\
$00: 27: 34.0737779$ & $117.0627^{\circ} \mathrm{E}, 38.1785^{\circ} \mathrm{N}$ & 75.5 & $00: 27: 34.087$ & 14 \\
$01: 21: 33.2457919$ & $117.5120^{\circ} \mathrm{E}, 38.3330^{\circ} \mathrm{N}$ & 135.2 & $01: 21: 33.281$ & 36 \\
\hline
\end{tabular}

also shows that the 00:23 sprite azimuth was horizontally displaced (16 and $4 \mathrm{~km}$, respectively, and the time delay is about $45 \mathrm{~ms}$ ) from the two +CGs, in agreement with results from $\mathrm{Lu}$ et al. (2013) that sprites with a time delay of more than $20 \mathrm{~ms}$ mostly have a horizontal displacement of more than $20 \mathrm{~km}$ from their parent CGs (Fig. 14a in their paper). From this point of view, the 00:23 sprite could be produced by these two +CGs together. On the other hand, the separation distance of $27 \mathrm{~km}$ between the two strokes is much smaller than the distance (about $13500 \mathrm{~km}$ ) between the strokes and the ELF magnetic field sensors at Syowa station, Antarctica. Therefore, the magnetic field signals produced by these two +CGs would be recorded by the sensor at almost the same time, making it impossible to distinguish either of them. The magnetic field measured by the ELF sensor would be the summation of the two +CGs.

The CMC of CG is an important indicator for sprite initiation ( $\mathrm{Hu}$ et al. 2002; Lu et al. 2013). According to the sprite QE heating theory in Pasko et al. (1997), sprites are predicted to be initiated at about $75 \mathrm{~km}$ with a CMC of $\sim 1000 \mathrm{C} \mathrm{km}$ (the charge of removal is $100 \mathrm{C}$, and the altitude is $10 \mathrm{~km}$ ), and $\sim 4000 \mathrm{C} \mathrm{km}$ (the altitude is also $10 \mathrm{~km}$, but the charge of removal is $400 \mathrm{C}$ ) is needed for optical emissions at $\sim 50-70 \mathrm{~km}$. In this study the ELF magnetic field $(1-100 \mathrm{~Hz})$ shown in Fig. 7 was used for the CMC estima- tion. The three sprite events have sprite-parent CG time delay about 45,14 , and $36 \mathrm{~ms}$, respectively. Because most positive lightning flashes (usually with only one return stroke) have return stroke duration on the order of a few tens of microseconds (the return stroke duration of negative strokes is on the same order), all of the three sprites occurred during the continuing current process (if the parent CGs had the continuous current). Therefore, the CMC estimation should include the return stroke and also the continuing current, which could be distinguished from the background.

For the convenience of readers, we briefly describe the CMC calculation. More detailed information can be found in Huang et al. (1999), Füllekrug and Constable (2000), Sato and Fukunishi (2003), and Sato et al. (2008). The Syowa station ELF system uses two orthogonal search coil magnetometers directing magnetic north-south (H-comp) and east-west (D-comp). The H- and D-comp magnetic field waveform data are first converted into the Theta- and Phaicomponents. Theta-comp corresponds to the magnetic field perturbations in the direction parallel to the wave propagation velocity, while the Phai-comp corresponds to those in the direction perpendicular to the wave propagation velocity. The magnetic field waveform data in the Phai-comp are then used for the $\mathrm{CMC}$ calculation. The following equation is used 
(a)

Syowa ELF Waveforms 00:23:24 Sprite
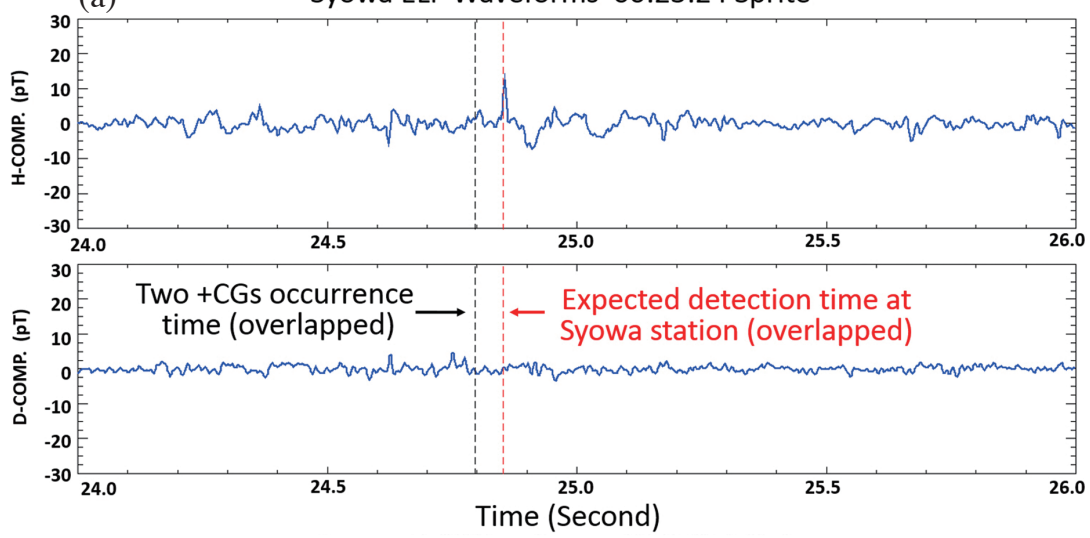

(b)

Syowa ELF Waveforms 00:27:34 Sprite
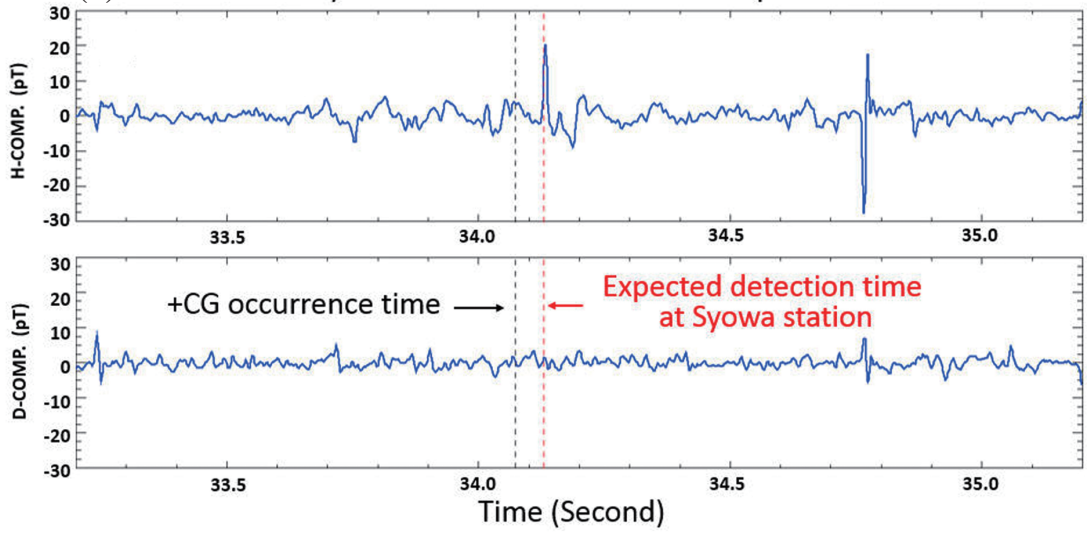

(c)

Syowa ELF Waveforms 01:21:33 Sprite
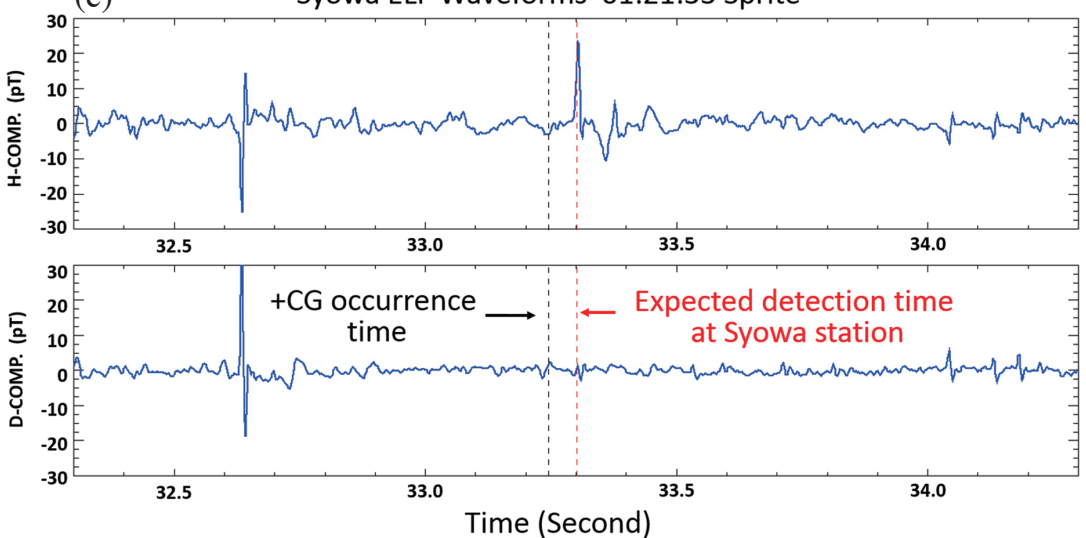

Fig. 7. ELF waveforms of the parent strokes for the three sprites. (a) 00:23:24 sprite, (b) 00:27:34 sprite, and (c) 01:21:33 sprite. The vertical dashed lines in black and red color represent the parent CG occurrence time and the expected detection time at Syowa station, respectively. Since the occurrence time of CG1 and CG2 (16:23:24.7955310 and 16:23:24.7955654) before the 00:23 sprite were very close to each other, the vertical lines were overlapped. (Color online only)

$H_{\phi}(f, \theta)=\frac{I \cdot d l(f)}{4 \pi R_{E} h_{0}} \sum_{n} \frac{2 n+1}{n(n+1)-v(v+1)} P_{n}^{1}(\cos \theta)$

where $H_{\phi}, f, \theta, I \cdot d l(f), R_{E}, h_{0}, n, v$, and $P_{n}^{1}$ are the observed magnetic field spectrum, the frequency, the angular distance between the observer and the source, the current moment spectrum of the source lightning, the radius of the
Earth, the ionospheric reflection height of the ELF wave, the mode number, the complex propagation constant and the associated Legendre polynomials for order $\mathrm{n}$ and first degree. It should be noted that there is also an ELF sensor in Onagawa station, Japan. We did not use Onagawa ELF data because the distance between the station and sprites are too close. Such close distance will cause large estimation errors in the CMC values. If the source-receiver distance is close 
$(0-2000 \mathrm{~km})$, the limited number of modes affects this theoretical model calculation and causes the large estimation error. This is also discussed in Füllekrug and Constable (2000). Therefore, we used Syowa ELF data and not Onagawa data. The distances between the sprite-producing +CG discharges and Syowa station are $\sim 13500 \mathrm{~km}$.

Since all the sprites delayed more than ten milliseconds from their parent CGs, the sprite occurred during the parent CG continuing current (if there was). The CMC values obtained here are the "total" CMCs of the parent CG discharges and include the return stroke part and also the continuing current part. On the other hand, we could not exclude background ELF signals excited by other CG discharges occurring somewhere else. However, the typical background ELF signal amplitude is about $5 \mathrm{pT}$, which would give about 10 $20 \%$ uncertainty in the detected ELF signal. The background ELF contribution was subtracted from the measured signal when calculating the $\mathrm{CMC}$ value. The calculated CMCs for the parent CGs for the three events are about 1478, 1582, and $2134 \mathrm{C} \mathrm{km}$, respectively. The above results show that the CMC value produced jointly by the two + CGs prior to the 00:23 sprite is smaller than that of the parent CGs (each parent CG has only one return stroke) for the sprites at 00:27 and 01:21 over the same thunderstorm. Since the CMC value of the lightning flash is the most important indicator for sprite initiation, that the total CMC value of the two +CGs is smaller than that of one parent CGs for other sprites over the same thunderstorm may indicate that the 00:23 sprite might be produced jointly by the two +CGs, and neither of them would be able to produce it alone.

Since the frequency range of the ELF magnetic field system in Syowa station is $1-100 \mathrm{~Hz}$, it cannot distinguish between two +CGs with a time difference of only few hundred microseconds. In order to show more information, the ELF/VLF magnetic field and vertical electric field (obtained in Taiwan) of the parent CG for the sprite at 00:23 were analyzed and shown in Fig. 8. The results show that clear pulses from the parent CG for the 00:23 sprite could be seen in the vertical electric field and magnetic field in the east-west direction (the main part of the magnetic field). The Fast Fourier transform (FFT) analysis on the vertical electric field and east-west magnetic field does not show much difference between the parent CGs for 00:23 and 00:27 sprites (due to the length limitation of this paper the figures are not shown). This may result from the fact that electromagnetic waves emitted by lightning flashes have very wide bandwidths (not monochromatic frequency). We suspect that electromagnetic waves radiated by CG1 and CG2 (or either of them) also have wide bandwidths. Therefore, there may not be a significant difference between the spectrum characteristics of the summation of CG1 and CG2 and either of them, which may explain the above conclusion that we got similar results from parent CGs for 00:23 sprite and 00:27 sprite.

In order to examine the thunderstorm structure underneath the recorded sprite clearly, radar reflectivity overlapped with negative and positive strokes, radar echo top overlapped with the two +CGs and vertical cross sections of radar reflectivity are shown in Fig. 2. Figure 2a clearly shows the radar reflectivity structure of the enlarged image of the ROI region (shown in Fig. 5g) overlapped with the 00:23 sprite azimuth and positive strokes (red "+") and negative ones (black "“”) within $10 \mathrm{~min}( \pm 5 \mathrm{~min})$ centered around the time of the sprite. The results show that most
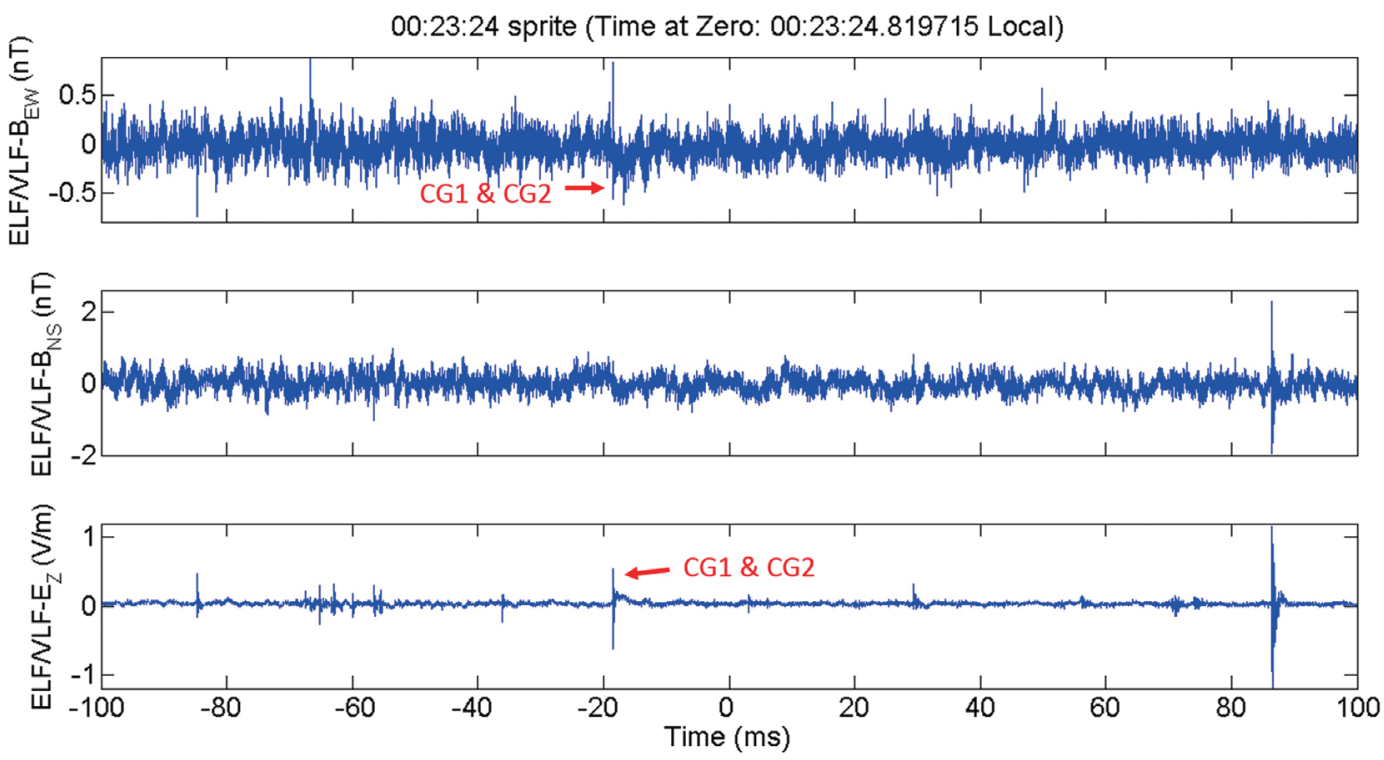

Fig. 8. ELF/VLF electric field and magnetic field waveforms of the parent strokes for the 00:23 sprite. CG1 and CG2 shown in the figure occurred at 00:23:24.8012460 and 00:23:24.8012804 (taking into account of the propagation delay), respectively. (Color online only) 
negative strokes are located in high radar reflectivity regions and positive ones in large stratiform regions with low radar reflectivity. The parent CG (the big red ' + ' in the figure) for the sprite at 00:27 was located in a thunderstorm region with radar reflectivity of about $25 \mathrm{dBZ}$. Considering the lightning location error $(760 \mathrm{~m})$, the parent $C G$ was located in a region with radar reflectivity no larger than $30 \mathrm{dBZ}$. The big black ' + ' in the figure, labeled with 'CG1' and 'CG2', respectively, represent the two +CGs before the 00:23 sprite, and their locations were also vertically aligned in the thunderstorm stratiform region.

Figure $2 \mathrm{~b}$ shows that $+\mathrm{CG} 1$ and $+\mathrm{CG} 2$ are vertically aligned with the radar echo tops about $6-8$ and $9-11 \mathrm{~km}$, respectively. Vertical cross sections of radar reflectivity along the line passing through $+\mathrm{CG} 1$ and +CG2 further show that CG1 and CG2 are located (vertically aligned) in the regions with radar echo top about 6 and $9 \mathrm{~km}$ (Fig. 2c), respectively, which is to some extent consistent with previous results that positive charges in thunderstorms at 4.1,6.1, and $8.2 \mathrm{~km}$ altitudes may play a dominant role in sprite production (Lyons et al. 2003; Lang et al. 2010). The maximum radar echo top along the sprite azimuth is lower than $12 \mathrm{~km}$, indicating that convection at the moment was not particularly strong, consistent with previous results that sprites usually occur over large stratiform regions (Lyons et al. 2003; Soula et al. 2010; Yang et al. 2013a, b, 2015).

It should be noted that the +CGs locations here were obtained using the lightning detection network and the source charge location transferred by the CG cannot be obtained from the data available. Using the very high frequency (VHF) technique, lightning detection network, sprite optical images and magnetic field measurement, Lu et al. (2013) analyzed 42 positive sprites in detail. They found that many parent CGs originated from the convective region, developed along a slanting path from the leading convection to the trailing stratiform, and then connected with the ground. $\mathrm{Lu}$ et al. (2013) also found that the original altitude of positive charge in most parent CGs is located between 5 and $10 \mathrm{~km}$. Based on these observations and Figs. 2a and b, we propose a thunderstorm electrical structure conceptual model for our observation (Fig. 2e).

The conceptual model shown in Fig. 2e indicates that the two positive CGs may be initiated in the thunderstorm convective region, then developed along a slanting path to the stratiform region and connected with the ground. The conceptual model is in agreement with the radar reflectivity (Fig. 2a) and radar echo top (Fig. 2b), and is also consistent with statistical observation results reported by $\mathrm{Lu}$ et al. (2013) and results obtained by Carey et al. (2005). In addition, the conceptual model is in good agreement with VHF observation of similar MCSs in the same region (Liu et al. 2013).

It should also be noted that the two + CGs are located (vertically aligned) in regions with different radar reflectiv- ity values (Fig. 2a) and different radar echo top (Fig. 2b), indicating that the two +CGs may locate in particle mixing region and the thunderstorm structures in these regions are very complex. Although the $+\mathrm{CG} 1$ and $+\mathrm{CG} 2$ locations are significantly separated, the positive charge reservoirs (from which the charge transferred to the ground) may be close to each other, and the in-cloud discharge may connect the two reservoirs together and play a role in sprite production (Ohkubo et al. 2005; Van der Velde et al. 2006; Marshall et al. 2007; Asano et al. 2009; Lu et al. 2013; Lyu et al. 2015). In this case, the two +CGs for the 00:23 sprite may be one lightning flash but with different locations (merely the distance between the ground striking points of the two strokes is larger than that of the grouping algorithm usually used for combing different return strokes into one flash). It is also interesting to note that Lu et al. (2013) analyzed a case of two sprites produced separately by two distinct return strokes in one flash. However, in this study, two distinct positive flashes possibly produced one sprite jointly.

\section{DISCUSSION}

The above results suggest that the two +CGs before the 00:23 sprite produced a total CMC of $1478 \mathrm{C} \mathrm{km}$. Statistical analysis by $\mathrm{Hu}$ et al. (2002) showed that the CMC of the parent CG of a sprite could be in the range of $120-3070$ $\mathrm{C} \mathrm{km}$, although they considered the $120 \mathrm{C} \mathrm{km}$ as an exceptional case. If we assume that each +CG before the 00:23 sprite contributed equally, namely, $739 \mathrm{C} \mathrm{km}$, which falls in the range reported by $\mathrm{Hu}$ et al. (2002). However, it should be noted that the CMC of the parent CG analyzed in $\mathrm{Hu}$ et al. (2002) is for short-delayed sprites, and the duration for CMC estimation was about $6 \mathrm{~ms}$, which is significantly shorter than the time delay of the 00:23 sprite. On the other hand, the CMC produced jointly by the two + CGs before the sprite at 00:23 is smaller than that of the other parent CGs (each parent CG has only one return stroke) for the sprites at 00:27 and 01:21 over the same thunderstorm, indicating that the required $\mathrm{CMC}$ for triggering sprites during this thunderstorm may be comparatively large. In addition, $739 \mathrm{C} \mathrm{km}$ is even lower than half of the parent CG CMC (1582 and $2134 \mathrm{C} \mathrm{km}$ ) for the other two sprites over the same thunderstorm, showing that neither of the two +CGs would be able to produce the 00:23 sprite. Therefore, the 00:23 sprite was possibly jointly produced by the two +CGs.

It should be noted that the optical images (Fig. 1) show that the sprite vertical extension was the smallest compared with that of the other two sprites recorded over the same thunderstorm. The optical images indicate that the sprite brightness in Fig. 1a was much dimmer than that in Fig. 1c, and the sprite brightness in Fig. 1a was also weaker than that in Fig. 1b (Fig. 3). All of these features may manifest that the electric field induced by the underlying lightning flashes for the sprite in Fig. 1a was not very strong, consistent with 
the small CMC obtained from the ELF magnetic field.

The CMC value produced by the two +CGs before the 00:23 sprite was smaller than that from the other parent CGs in the same thunderstorm. It is more likely that the 00:23 sprite was produced by both of them. However, the possibility that the sprite was produced by a single lightning stroke with a small CMC of $739 \mathrm{C} \mathrm{km}$ cannot be totally excluded. There may be a different relationship between the two +CGs and the total $\mathrm{CMC}$ value. For example, the first $+\mathrm{CG}$ might be an initial return stroke having small CMC values, while the second one is the subsequent return stroke having large CMC values, vice versa. Or the two +CGs had almost equal $\mathrm{CMC}$ values. Considering the discharge processes of the two +CGs, there also may be several scenarios. Either of the two +CGs or each of them could contain a continuous current process. Or one $+\mathrm{CG}$ occurred and was followed by a continuing current during which the second $+\mathrm{CG}$ occurred. It also could be possible that one +CG occurred and followed by the second $+\mathrm{CG}$ with a continuing current.

Qin et al. (2012) showed that the minimum CMC for initiating a positive sprite could be as small as $\sim 200 \mathrm{C} \mathrm{km}$, and vertically elongated inhomogeneity in electron density are found to be more favorable for sprite initiation. Results from simulation work conducted by Liu et al. (2012) showed that positive streamers could be initiated from the tip of an ionization column in a uniform applied electric field well below the breakdown threshold field and discussed the importance of inhomogeneities. Studies by Kosar et al. (2012) showed that when an appropriate ionization column is introduced, the streamer could be initiated in a variety of electric fields with the lowest electric field of $0.3 \mathrm{E}_{\mathrm{k}}\left(\mathrm{E}_{\mathrm{k}}\right.$ is the breakdown threshold field). Kosar et al. (2013) further indicated that positive streamers can be initiated at subbreakdown conditions from the inhomogeneities with a density comparable to sprite halo densities, also showing the importance of inhomogeneities in sprite initiation. These results show that except for the CMC value of the lightning there are also other factors that play roles in sprite initiation.

\section{CONCLUSION}

Three positive sprites were recorded over a mesoscale convective system in northeast China. Although the thunderstorm lasted more than $10 \mathrm{hr}$, the observed sprites occurred within a comparatively narrow time window (less than one hour). The lightning detection network data and ELF magnetic field recorded at Syowa station show that the sprites occurring at 00:27 and 01:21, respectively, were produced by positive CGs with single return stroke and their following continuing current. Both of these sprites occurred during the continuing current period.

Thousands of positive sprites have been reported in the literature since the discovery of sprites. However, the sprite at 00:23 analyzed in this study is unusual and unique because it was possibly produced by two distinct positive CGs occurring within a very short time difference but with largely separated $(\sim 27 \mathrm{~km})$ locations. This discovery provides new insights into positive sprite production. Negative strokes dominated during the thunderstorm life cycle. The three sprites occurred during a time period in which both negative and positive strokes were active. All three sprites occurred over the thunderstorm stratiform region in which lightning activity is not as active as in convective regions.

The parent CG CMC estimated from the ELF magnetic field, including the contributions from both the return stroke and continuing current, for the three sprites were about 1478,1582 , and $2134 \mathrm{C} \mathrm{km}$, respectively. The CMC values for the parent CGs are in good agreement with the sprite vertical extensions (the smaller the CMC value, the shorter the vertical extension) and optical arbitrary brightness (the smaller the CMC value, the dimmer the sprite brightness). The conceptual thunderstorm electrical structure model is consistent with the previous observation results and is also in good agreement with the VHF observations of similar thunderstorms in the same region.

Acknowledgements This research was supported jointly by the National Natural Science Foundation of China (Grant No. 41374153, 41574141), the Youth Innovation Promotion Association of the Chinese Academy of Sciences (2013053), the high resolution Earth observation funds for young scientists (Grant No. GFZX04060103-7-11), and the Yellow River Delta Ecology Research Station of Coastal Wetland, Chinese Academy of Sciences.

\section{REFERENCES}

Abarca, S. F., K. L. Corbosiero, and T. J. Galarneau Jr., 2010: An evaluation of the Worldwide Lightning Location Network (WWLLN) using the National Lightning Detection Network (NLDN) as ground truth. J. Geophys. Res., 115, D18206, doi: 10.1029/2009JD013411. [Link]

Asano, T., T. Suzuki, M. Hayakawa, and M. G. Cho, 2009: Three-dimensional EM computer simulation on sprite initiation above a horizontal lightning discharge. $J$. Atmos. Sol.-Terr. Phys., 71, 983-990, doi: 10.1016/j. jastp.2009.04.003. [Link]

Barrington-Leigh, C. P., U. S. Inan, and M. Stanley, 2001: Identification of sprites and elves with intensified video and broadband array photometry. J. Geophys. Res., 106, 1741-1750, doi: 10.1029/2000JA000073. [Link]

Boccippio, D. J., E. R. Williams, S. J. Heckman, W. A. Lyons, I. T. Baker, and R. Boldi, 1995: Sprites, ELF transients, and positive ground strokes. Science, 269, 10881091, doi: 10.1126/science.269.5227.1088. [Link]

Boggs, L. D., N. Liu, M. Splitt, S. Lazarus, C. Glenn, H. Rassoul, and S. A. Cummer, 2016: An analysis of five 
negative sprite-parent discharges and their associated thunderstorm charge structures. J. Geophys. Res., 121,759-784, doi: 10.1002/2015JD024188. [Link]

Bovalo, C., C. Barthe, N. Yu, N. Yu, and N. Begue, 2014: Lightning activity within tropical cyclones in the South West Indian Ocean. J. Geophys. Res., 119, 8231-8244, doi: 10.1002/2014JD021651. [Link]

Carey, L. D., M. J. Murphy, T. L. McCormick, and N. W. S. Demetriades, 2005: Lightning location relative to storm structure in a leading-line, trailing-stratiform mesoscale convective system. J. Geophys. Res., 110, D03105, doi: 10.1029/2003JD004371. [Link]

Chang, S. C., R. R. Hsu, S. M. Huang, H. T. Su, C. L. Kuo, J. K. Chou, L. J. Lee, Y. J. Wu, and A. B. Chen, 2014: Characteristics of TLE-producing lightning in a coastal thunderstorm. J. Geophys. Res., 119, 9303-9320, doi: 10.1002/2014ja019819. [Link]

Chou, J. K., L. Y. Tsai, C. L. Kuo, Y. J. Lee, C. M. Chen, A. B. Chen, H. T. Su, R. R. Hsu, P. L. Chang, and L. C. Lee, 2011: Optical emissions and behaviors of the blue starters, blue jets, and gigantic jets observed in the Taiwan transient luminous event ground campaign.J.Geophys. Res., 116, A07301, doi: 10.1029/2010ja016162. [Link]

Cummer, S. A. and W. A. Lyons, 2004: Lightning charge moment changes in U.S. High Plains thunderstorms. Geophys. Res. Lett., 31, L05114, doi: 10.1029/2003GL019043. [Link]

Cummer, S. A. and W. A. Lyons, 2005: Implications of lightning charge moment changes for sprite initiation.J.Geophys. Res., 110, A04304, doi: 10.1029/2004JA010812. [Link]

Cummer, S. A., N. C. Jaugey, J. B. Li, W. A. Lyons, T. E. Nelson, and E. A. Gerken, 2006: Submillisecond imaging of sprite development and structure. Geophys. Res. Lett., 33, L04104, doi: 10.1029/2005GL024969. [Link]

Cummins, K. L., M. J. Murphy, E. A. Bardo, W. L. Hiscox, R. B. Pyle, and A. E. Pifer, 1998: A combined TOA/ MDF technology upgrade of the U.S. National Lightning Detection Network. J. Geophys. Res., 103, 90359044, doi: 10.1029/98JD00153. [Link]

Feng, G., X. Qie, J. Wang, and D. Gong, 2009: Lightning and Doppler radar observations of a squall line system. Atmos. Res., 91, 466-478, doi: 10.1016/j.atmosres.2008.05.015. [Link]

Franz, R. C., R. J. Nemzek, and J. R. Winckler, 1990: Television image of a large upward electrical discharge above a thunderstorm system. Science, 249, 48-51, doi: 10.1126/science. 249.4964.48. [Link]

Frey, H. U., S. B. Mende, S. A. Cummer, J. Li, T. Adachi, H. Fukunishi, Y. Takahashi, A. B. Chen, R. R. Hsu, H. T. Su, and Y. S. Chang, 2007: Halos generated by negative cloud-to-ground lightning. Geophys. Res. Lett.,
34, L18801, doi: 10.1029/2007GL030908. [Link]

Fukunishi, H., Y. Takahashi, M. Kubota, K. Sakanoi, U. S. Inan, and W. A. Lyons, 1996: Elves: Lightning-induced transient luminous events in the lower ionosphere. Geophys.Res.Lett., 23, 2157-2160, doi: 10.1029/96GL01979. [Link]

Füllekrug, M. and S. Constable, 2000: Global triangulation of intense lightning discharges. Geophys. Res. Lett., 27, 333-336, doi: 10.1029/1999GL003684. [Link]

Hardman, S. F., R. L. Dowden, J. B. Brundell, J. L. Bahr, Z. Kawasaki, and C. J. Rodger, 2000: Sprite observations in the Northern Territory of Australia. J. Geophys. Res., 105, 4689-4697, doi: 10.1029/1999JD900325. [Link]

Hsu, R. R., H. T. Su, A. B. Chen, L. C. Lee, M. Asfur, C. Price, and Y. Yair , 2003: Transient luminous events in the vicinity of Taiwan. J. Atmos. Sol.-Terr. Phys., 65, 561-566, doi: 10.1016/S1364-6826(02)00320-6. [Link]

Hu, W., S. A. Cummer, W. A. Lyons, and T. E. Nelson, 2002: Lightning charge moment changes for the initiation of sprites. Geophys. Res. Lett., 29, 1279, doi: 10.1029/2001GL014593. [Link]

Huang, E., E. Williams, R. Boldi, S. Heckman, W. Lyons, M. Taylor, T. Nelson, and C. Wong, 1999: Criteria for sprites and elves based on Schumann resonance observations. J. Geophys. Res., 104, 16943-16964, doi: 10.1029/1999JD900139. [Link]

Huang, S. M., R. R. Hsu, L. J. Lee, H. T. Su, C. L. Kuo, C. C. Wu, J. K. Chou, S. C. Chang, Y. J. Wu, and A. B. Chen, 2012: Optical and radio signatures of negative gigantic jets: Cases from Typhoon Lionrock (2010). J. Geophys. Res., 117, A08307, doi: 10.1029/2012ja017600. [Link]

Inan, U. S., W. A. Sampson, and Y. N. Taranenko, 1996: Space-time structure of optical flashes and ionization changes produced by lighting-EMP. Geophys. Res. Lett., 23, 133-136, doi: 10.1029/95GL03816. [Link]

Inan, U. S., C. Barrington-Leigh, S. Hansen, V. S. Glukhov, T. F. Bell, and R. Rairden, 1997: Rapid lateral expansion of optical luminosity in lightning-induced ionospheric flashes referred to as 'elves'. Geophys. Res. Lett., 24, 583-586, doi: 10.1029/97GL00404. [Link]

Kosar, B. C., N. Y. Liu, and H. K. Rassoul, 2012: Luminosity and propagation characteristics of sprite streamers initiated from small ionospheric disturbances at subbreakdown conditions. J. Geophys. Res., 117, A08328, doi: 10.1029/2012JA017632. [Link]

Kosar, B. C., N. Y. Liu, and H. K. Rassoul, 2013: Formation of sprite streamers at subbreakdown conditions from ionospheric inhomogeneities resembling observed sprite halo structures. Geophys. Res. Lett., 40, 62826287, doi: 10.1002/2013GL058294. [Link]

Kuo, C. L., A. B. Chen, Y. J. Lee, L. Y. Tsai, R. K. Chou, R. R. Hsu, H. T. Su, L. C. Lee, S. A. Cummer, H. U. 
Frey, S. B. Mende, Y. Takahashi, and H. Fukunishi, 2007: Modeling elves observed by FORMOSAT-2 satellite. J. Geophys. Res., 112, A11312, doi: 10.1029/2007JA012407. [Link]

Kuo, C. L., J. K. Chou, L. Y. Tsai, A. B. Chen, H. T. Su, R. R. Hsu, S. A. Cummer, H. U. Frey, S. B. Mende, Y. Takahashi, and L. C. Lee, 2009: Discharge processes, electric field, and electron energy in ISUAL-recorded gigantic jets. J. Geophys. Res., 114, A04314, doi: 10.1029/2008JA013791. [Link]

Lang, T. J., W. A. Lyons, S. A. Rutledge, J. D. Meyer, D. R. MacGorman, and S. A. Cummer, 2010: Transient luminous events above two mesoscale convective systems: Storm structure and evolution. J. Geophys. Res., 115, A00E22, doi: 10.1029/2009JA014500. [Link]

Li, J., S. A. Cummer, W. A. Lyons, and T. E. Nelson, 2008: Coordinated analysis of delayed sprites with high-speed images and remote electromagnetic fields. J. Geophys. Res., 113, D20206, doi: 10.1029/2008jd010008. [Link]

Li, J., S. Cummer, G. Lu, and L. Zigoneanu, 2012: Charge moment change and lightning-driven electric fields associated with negative sprites and halos. J. Geophys. Res., 117, A09310, doi: 10.1029/2012JA017731. [Link]

Liu, D., 2010: The characteristics of lightning activities and numerical simulation of the charge structure in thunderstorm. Ph.D. Thesis, Institute of Atmospheric Physics, Chinese Academy of Sciences.

Liu, D., X. S. Qie, Z. C. Wang, X. K. Wu, and L. X. Pan, 2013: Characteristics of lightning radiation source distribution and charge structure of squall line. Acta. Phys. Sin., 62, doi: 10.7498/aps.62.219201. [Link]

Liu, N. Y. and V. P. Pasko, 2004: Effects of photoionization on propagation and branching of positive and negative streamers in sprites. J. Geophys. Res., 109, A04301, doi: 10.1029/2003ja010064. [Link]

Liu, N. Y., B. Kosar, S. Sadighi, J. R. Dwyer, and H. K. Rassoul, 2012: Formation of streamer discharges from an isolated ionization column at subbreakdown conditions. Phys. Rev. Lett., 109, 025002, doi: 10.1103/ PhysRevLett.109.025002. [Link]

Liu, N. Y., M. G. McHarg, and H. C. Stenbaek-Nielsen, 2015a: High-altitude electrical discharges associated with thunderstorms and lightning. J. Atmos. Sol.-Terr. Phys., 136, 98-118, doi: 10.1016/j.jastp.2015.05.013. [Link]

Liu, N. Y., N. Spiva, J. R. Dwyer, H. K. Rassoul, D. Free, and S. A. Cummer, 2015b: Upward electrical discharges observed above Tropical Depression Dorian. Nat. Comm., 6, doi: 10.1038/ncomms6995. [Link]

Liu, N. Y., J. R. Dwyer, H. C. Stenbaek-Nielsen, and M. G. McHarg, 2015c: Sprite streamer initiation from natural mesospheric structures. Nat. Comm., 6, doi: 10.1038/ ncomms8540. [Link]

Liu, Y., L. Y. Chan, Q. Lin, W. Feng, X. Bi, J. Chen, H. Tao, X. Wang, D. Chen, G. Sheng, and J. Fu, 2014: Physical and observable characteristics of cloud-toground lightning over the Pearl River Delta region of South China. J. Geophys. Res., 119, 5986-5999, doi: 10.1002/2014JD021559. [Link]

Lu, G., S. A. Cummer, R. J. Blakeslee, S. Weiss, and W. H. Beasley, 2012: Lightning morphology and impulse charge moment change of high peak current negative strokes. J. Geophys. Res., 117, D04212, doi: 10.1029/2011JD016890. [Link]

Lu, G., S. A. Cummer, J. Li, L. Zigoneanu, W. A. Lyons, M. A. Stanley, W. Rison, P. R. Krehbiel, H. E. Edens, R. J. Thomas, W. H. Beasley, S. A. Weiss, R. J. Blakeslee, E. C. Bruning, D. R. MacGorman, T. C. Meyer, K. Palivec, T. Ashcraft, and T. Samaras, 2013: Coordinated observations of sprites and in-cloud lightning flash structure. J. Geophys. Res., 118, 6607-6632, doi: 10.1002/jgrd.50459. [Link]

Lu, M.-R., P.-Y. Chen, C.-L. Kuo, C.-C. Chou, B.-X. Wu, S. Abe, H.-T. Su, R.-R. Hsu, S.-H. Wang, N.-H. Lin, and L.-C. Lee, 2017: Recent work on sprite spectrum in Taiwan. Terr. Atmos. Ocean. Sci., 28, 625-636, doi: 10.3319/TAO.2016.08.26.02. [Link]

Lyons, W. A., 1994: Characteristics of luminous structures in the stratosphere above thunderstorms as imaged by low-light video. Geophys. Res. Lett., 21, 875-878, doi: 10.1029/94GL00560. [Link]

Lyons, W. A., 1996: Sprite observations above the U.S. High Plains in relation to their parent thunderstorm systems. J. Geophys. Res., 101, 29641-29652, doi: 10.1029/96JD01866. [Link]

Lyons, W. A., T. E. Nelson, E. R. Williams, S. A. Cummer, and M. A. Stanley, 2003: Characteristics of sprite-producing positive cloud-to-ground lightning during the 19 July 2000 STEPS mesoscale convective systems. Mon. Weather Rev., 131, 2417-2427, doi: 10.1175/152 0-0493(2003)131<2417:COSPCL>2.0.CO;2. [Link]

Lyu, F., S. A. Cummer, and L. McTague, 2015: Insights into high peak current in-cloud lightning events during thunderstorms. Geophys. Res. Lett., 42, 6836-6843, doi: 10.1002/2015GL065047. [Link]

Marshall, R. A., U. S. Inan, and W. A. Lyons, 2007: Very low frequency sferic bursts, sprites, and their association with lightning activity. J. Geophys. Res., 112, D22105, doi: 10.1029/2007JD008857. [Link]

Neubert. T., T. H. Allin, H. Stenbaek-Nielsen, and E. Blanc, 2001: Sprites over Europe. Geophys. Res. Lett., 28, 3585-3588, doi: 10.1029/2001GL013427. [Link]

Ohkubo, A., H. Fukunishi, Y. Takahashi, and T. Adachi, 2005: VLF/ELF sferic evidence for in-cloud discharge activity producing sprites. Geophys. Res. Lett., 32, L04812, doi: 10.1029/2004GL021943. [Link] 
Pan, L. X., X. S. Qie, D. X. Liu, D. F. Wang, and J. Yang, 2009: The lightning activities in super typhoons over the Northwest Pacific. Sci. China Earth Sci., 53, 12411248, doi: 10.1007/s11430-010-3034-z. [Link]

Pasko, V. P., 2003: Atmospheric physics: Electric jets. $\mathrm{Na}$ ture, 423, 927-929, doi: 10.1038/423927a. [Link]

Pasko, V. P., U. S. Inan, T. F. Bell, and Y. N. Taranenko, 1997: Sprites produced by quasi-electrostatic heating and ionization in the lower ionosphere. J. Geophys. Res., 102, 4529-4561, doi: 10.1029/96JA03528. [Link]

Pasko, V. P., M. A. Stanley, J. D. Matthews, U. S. Inan, and T. G. Wood, 2002: Electrical discharge from a thundercloud top to the lower ionosphere. Nature, 416, 152-154, doi: 10.1038/416152a. [Link]

Peng, K.-M., R.-R. Hsu, H.-T. Su, A. Chen, J.-K. Chou, S.C. Chang, Y.-J. Wu, C.-L. Hung, I.-C. Yang, and S.-H. Tsai, 2017: Transient luminous event coordinated observations using FORMOSAT-2 satellite and Taiwan sprites campaign. Terr. Atmos. Ocean. Sci., 28, 597608, doi: 10.3319/TAO.2016.09.21.03. [Link]

Pinto, O., M. M. F. Saba, R. C. A. Pinto, F. S. S. Tavares, K. P. Naccarato, N. N. Solorzano, M. J. Taylor, P. D. Pautet, and R. H. Holzworth, 2004: Thunderstorm and lightning characteristics associated with sprites in Brazil. Geophys. Res. Lett., 31, L13103, doi: 10.1029/2004GL020264. [Link]

Qin, J., S. Celestin, and V. P. Pasko, 2012: Minimum charge moment change in positive and negative cloud to ground lightning discharges producing sprites. Geophys. Res. Lett., 39, L22801, doi: 10.1029/2012GL053951. [Link]

Rakov, V. A. and M. A. Uman, 2003: Lightning: Physics and Effects, Cambridge University Press, Cambridge, U.K., 687 pp.

São Sabbas, F. T., D. D. Sentman, E. M. Wescott, O. Pinto Jr., O. Mendes Jr., and M. J. Taylor, 2003: Statistical analysis of space-time relationships between sprites and lightning. J. Atmos. Sol.-Terr. Phys., 65, 525-535, doi: 10.1016/S1364-6826(02)00326-7. [Link]

Sato, M. and H. Fukunishi, 2003: Global sprite occurrence locations and rates derived from triangulation of transient Schumann resonance events. Geophys. Res. Lett., 30, doi: 10.1029/2003GL017291. [Link]

Sato, M., H. Fukunishi, M. Kikuchi, H. Yamagishi, and W. A. Lyons, 2003: Validation of sprite-inducing cloud-toground lightning based on ELF observations at Syowa station in Antarctica.J. Atmos. Sol.-Terr.Phys., 65, 607614, doi: 10.1016/S1364-6826(02)00327-9. [Link]

Sato, M., Y. Takahashi, A. Yoshida, and T. Adachi, 2008: Global distribution of intense lightning discharges and their seasonal variations. J. Phys. D: Appl. Phys., 41, 234011, doi: 10.1088/0022-3727/41/23/234011. [Link]
Sato, M., T. Adachi, T. Ushio, T. Morimoto, M. Kikuchi, H. Kikuchi, M. Suzuki, A. Yamazaki, Y. Takahashi, R. Ishida, Y. Sakamoto, K. Yoshida, and Y. Hobara, 2017: Sprites identification and their spatial distributions in JEM-GLIMS nadir observations. Terr. Atmos. Ocean. Sci., 28, 545-561, doi: 10.3319/TAO.2016.09.21.02. [Link]

Savtchenko, A., R. Mitzeva, B. Tsenova, and S. Kolev, 2009: Analysis of lightning activity in two thunderstorm systems producing sprites in France. $J$. Atmos. Sol.-Terr. Phys., 71, 1277-1286, doi: 10.1016/j. jastp.2009.04.010. [Link]

Sentman, D. D., E. M. Wescott, D. L. Osborne, D. L. Hampton, and M. J. Heavner, 1995: Preliminary results from the Sprites94 aircraft campaign: 1. Red sprites. Geophys. Res. Lett., 22, 1205-1208, doi: 10.1029/95GL00583. [Link]

Shalev, S., H. Saaroni, T. Izsak, Y. Yair, and B. Ziv, 2011: The spatio-temporal distribution of lightning over Israel and the neighboring area and its relation to regional synoptic systems. Nat. Hazards Earth Syst. Sci., 11, 2125-2135, doi: 10.5194/nhess-11-2125-2011. [Link]

Soula, S., O. van der Velde, J. Palmiéri, O. Chanrion, T. Neubert, J. Montanyà, F. Gangneron, Y. Meyerfeld, F. Lefeuvre, and G. Lointier, 2010: Characteristics and conditions of production of transient luminous events observed over a maritime storm. J. Geophys. Res., 115, D16118, doi: 10.1029/2009JD012066. [Link]

Stanley, M., P. Krehbiel, M. Brook, C. Moore, W. Rison, and B. Abrahams, 1999: High speed video of initial sprite development. Geophys. Res. Lett., 26, 32013204, doi: 10.1029/1999GL010673. [Link]

Stenbaek-Nielsen, H. C., D. R. Moudry, E. M. Wescott, D. D. Sentman, and F. T. S. Sabbas, 2000: Sprites and possible mesospheric effects. Geophys. Res. Lett., 27, 3829-3832, doi: 10.1029/2000GL003827. [Link]

Stenbaek-Nielsen, H. C., R. Haaland, M. G. McHarg, B. A. Hensley, and T. Kanmae, 2010: Sprite initiation altitude measured by triangulation. J. Geophys. Res., 115, A00E12, doi: 10.1029/2009ja014543. [Link]

Su, H. T., R. R. Hsu, A. B. C. Chen, Y. J. Lee, and L. C. Lee, 2002: Observation of Sprites over the Asian continent and over oceans around Taiwan. Geophys. Res. Lett., 29, doi: 10.1029/2001GL013737. [Link]

Su, H. T., R. R. Hsu, A. B. Chen, Y. C. Wang, W. S. Hsiao, W. C. Lai, L. C. Lee, M. Sato, and H. Fukunishi, 2003: Gigantic jets between a thundercloud and the ionosphere. Nature, 423, 974-976, doi: 10.1038/nature01759. [Link]

Suzuki, T., Y. Matsudo, T. Asano, M. Hayakawa, and K. Michimoto, 2011: Meteorological and electrical aspects of several winter thunderstorms with sprites in the Hokuriku area of Japan. J. Geophys. Res., 116, D06205, doi: 10.1029/2009JD013358. [Link] 
Van der Velde, O. A., Á. Mika, S. Soula, C. Haldoupis, T. Neubert, and U. S. Inan, 2006: Observations of the relationship between sprite morphology and in-cloud lightning processes. J. Geophys. Res., 111, D15203, doi: 10.1029/2005JD006879. [Link]

Van der Velde, O. A., W. A. Lyons, T. E. Nelson, S. A. Cummer, J. Li, and J. Bunnell, 2007: Analysis of the first gigantic jet recorded over continental North America. J. Geophys. Res., 112, D20104, doi: 10.1029/2007JD008575. [Link]

Wescott, E. M., D. D. Sentman, M. J. Heavner, D. L. Hampton, D. L. Osborne, and O. H. Vaughan Jr., 1996: Blue starters: Brief upward discharges from an intense Arkansas thunderstorm. Geophys. Res. Lett., 23, 21532156, doi: 10.1029/96GL01969. [Link]

Wescott, E. M., H. C. Stenbaek-Nielsen, D. D. Sentman, M. J. Heavner, D. R. Moudry, and F. T. S. Sabbas, 2001: Triangulation of sprites, associated halos and their possible relation to causative lightning and micrometeors. J. Geophys. Res., 106, 10467-10477, doi: 10.1029/2000JA000182. [Link]

Winckler, J. R., W. A. Lyons, T. E. Nelson, and R. J. Nemzek, 1996: New high-resolution ground-based studies of sprites. J. Geophys. Res., 101, 6997-7004, doi: 10.1029/95JD03443. [Link]

Wu, Y.-J., R.-R. Hsu, A. B.-C. Chen, H.-T. Su, S.-C. Chang, J.-K. Chou, Y.-J. Lee, and K.-M. Peng, 2017: Revisiting oceanic elves and lightning occurrence rate dur- ing El Niño and La Niña episodes over a 10-year time frame. Terr. Atmos. Ocean. Sci., 28, 571-581, doi: 10.3319/TAO.2016.07.28.01. [Link]

Yang, J. and G. Feng, 2012: A gigantic jet event observed over a thunderstorm in mainland China. Chin. Sci. Bull., 57, 4791-4800, doi: 10.1007/s11434-012-54863. [Link]

Yang, J., X. Qie, G. Zhang, Y. Zhao, and T. Zhang, 2008: Red sprites over thunderstorms in the coast of Shandong province, China. Chin. Sci. Bull., 53, 1079-1086, doi: 10.1007/s11434-008-0141-8. [Link]

Yang, J., X. Qie, and G. Feng, 2013a: Characteristics of one sprite-producing summer thunderstorm. Atmos. Res., 127, 90-115, doi: 10.1016/j.atmosres.2011.08.001. [Link]

Yang, J., M. Yang, C. Liu, and G. Feng, 2013b: Case studies of sprite-producing and non-sprite-producing summer thunderstorms. Adv. Atmos. Sci., 30, 1786-1808, doi: 10.1007/s00376-013-2120-5. [Link]

Yang, J., G. Lu, L. J. Lee, and G. Feng, 2015: Long-delayed bright dancing sprite with large horizontal displacement from its parent flash. J. Atmos. Sol.-Terr. Phys., 129, 1-5, doi: 10.1016/j.jastp.2015.04.001. [Link]

Zhang, Y., S. Yang, W. Lu, D. Zheng, W. Dong, B. Li, S. Chen, Y. Zhang, and L. Chen, 2014: Experiments of artificially triggered lightning and its application in Conghua, Guangdong, China. Atmos. Res., 135-136, 330-343, doi: 10.1016/j.atmosres.2013.02.010. [Link] 